\title{
A comparative study of friction factor correlations for high concentrate slurry flow in smooth pipes
}

\author{
K. M. Assefa, D. R. Kaushal \\ Department of Civil Engineering, Indian Institute of Technology Delhi, Hauz Khas, New Delhi 110016, India. \\ ${ }^{*}$ Corresponding author. E-mail: kaushal@civil.iitd.ac.in
}

\begin{abstract}
A number of correlations for friction factor determinations in smooth pipes have been proposed in the past decades. The accuracy and applicability of these friction factor formulas should be examined. Based on this notion the paper is designed to provide a comparative study of friction factor correlations in smooth pipes for all flow regimes of Bingham fluids. Nine models were chosen. The comparisons of the selected equations with the existing experimental results, which are available in the literature, were expressed through MARE, MRE ${ }^{+}$MRE, RMSE, $\Theta$, and S. The statistical comparisons were also carried out using MSC and AIC. The analyses show that the Wilson-Thomas (1985) and Morrison (2013) models are best fit models to the experimental data for the Reynolds number up to 40000. Within this range, both models can be used alternately. But beyond this Re value the discrepancy of the Wilson-Thomas model is higher than the Morrison model. In view of the fact that the Morrison model requires fewer calculations and parameters as well as a single equation is used to compute the friction factor for all flow regimes, it is the authors' advice to use this model for friction factor estimation for the flow of Bingham fluids in smooth pipes as an alternative to the Moody chart and other implicit formulae.
\end{abstract}

Keywords: Bingham fluid; Smooth pipe; Laminar flow; Turbulent flow; Friction factor; Reynolds number; Correlations; Statistical parameters.

\section{INTRODUCTION}

Slurry pipelines are emerging technologies for long distance transportation of bulk materials such as coal, iron ore, dredging and tailings disposal. This slurry transportation system is considered to be significant, for its special characteristics such as safety, reliability and friendliness to the environment plus its relatively low operational and maintenance costs. In design of these pipelines for Newtonian and non-Newtonian fluids one of the most important technical parameters is the pressure drop as it influences the requirement of pumping energy. The pressure drop is produced by the internal friction of the slurry and friction between the pipe and the slurry. This interaction is commonly expressed as a dimensionless factor called friction factor. For flow in smooth pipes this friction factor is found to be a function the Reynolds number which in turn primarily depends on the slurry properties (velocity, density, and viscosity) and pipe diameter. Several studies for friction factor prediction in slurry flow for smooth pipes are available in the literature (Danish et al., 2011; Darby and Melson, 1981; Moody, 1944; Morrison, 2013; Swamee and Aggarwal, 2011; Swamee and Jain, 1976; etc.). Some of the empirical correlations claim to apply to all flow regimes (Morrison, 2013) and others are restricted to one or two flow regimes only (Danish et al., 2011; Darby and Melson, 1981; etc.).

For laminar flow, the correlation between friction factor and Reynolds number is well established (Moody, 1944; Swamee and Aggarwal, 2011). However, the prediction of the friction factor in the turbulent regime is still one of the difficult theoretical and practical problems. The well-known friction factor in the Darcy-Weisbach equation for pressure drop estimation for laminar and turbulent flow is given by Hagen-Poiseuille equation and the implicit Colebrook - White equation, respectively. Due to their demonstrated applicability, these equations have become the accepted standard for calculation of the friction factor. The Moody chart (1944) for friction factor is plotted based on these equations. The implicit form of the ColebrookWhite equation for turbulent flow disables the quick estimation of friction factor in hand calculations. For these reasons, many attempts were made in the recent past to calculate the value of friction factor with explicit relations.

The basic intention of the present study is to compute the friction factor for flow of Bingham fluids in smooth pipes by various equations for the experimental data available in literature. The best representative model in order to obtain good results for the experimental data is then decided.

\section{THE EXISTING FRICTION FACTORS RELATIONS}

The following equations were selected for computing friction factor in laminar, and/or turbulent flow regimes and presented in chronological order.

\section{Hagen and Poiseuille (1840) equation}

It is a simple and the most common formula to estimate the friction factor in laminar flow. It is used to construct a Moody chart for the laminar flow regime. It is given by:

$$
\begin{array}{cc}
f=\frac{64}{R e} & R e \leq 2100 \\
\text { where } & \operatorname{Re}=\frac{U \rho_{m} D}{\eta_{p}}
\end{array}
$$

\section{Blasius correlations (1913)}

It is the simplest numerical equation for solving the friction factor in turbulent flow. It is valid only for smooth pipes and up to the Reynolds number $10^{5}$. As cited by Fang et al., (2011) the friction factor is given as: 


$$
\begin{array}{ll}
f=0.316(R e)^{-1 / 4} & \text { for } 2100<R e \leq 2 \times 10^{4} \\
f=0.184(R e)^{-1 / 5} & \text { for } R e \geq 2 \times 10^{4}
\end{array}
$$

\section{The Buckingham-Reiner equation}

A precise description of friction loss for Bingham plastics in fully developed laminar pipe flow was first published by Buckingham (1921). His expression can be written as:

$f_{L}=\frac{64}{\operatorname{Re}}\left[1+\frac{H e}{6 R e}-\frac{64}{3}\left(\frac{H e^{4}}{f_{L}^{3} \operatorname{Re}^{7}}\right)\right]$

where $H e=\frac{\tau_{y} \rho_{m} D^{2}}{\eta_{p}}$

Although an exact analytical solution of the BuckinghamReiner equation can be obtained because it is a fourth order polynomial equation in $f$, due to complexity of the solution it is rarely employed. Therefore, researchers have tried to develop explicit approximations for the Buckingham-Reiner equation.

\section{Colebrook-White equation (1933)}

If the relative roughness is taken as negligible, he suggested the following implicit formula for smooth pipes:

$\frac{1}{\sqrt{f}}=2 \log _{10}\left(\frac{2.51}{\operatorname{Re} \sqrt{f}}\right)$

He also developed an explicit equation for smooth pipes to estimate the friction factor as:

$\frac{1}{\sqrt{f}}=1.8 \log _{10}\left(\frac{R e}{6.9}\right)$

The validity of this equation was reported for Reynolds number of $4000 \leq \operatorname{Re} \leq 10^{8}$

\section{Prandtl correlation (1935)}

It is not explicit in friction factor and must be solved iteratively. This is good only for $R e$ in the range of 4000 to $10^{6}$. The formula has the following forms:

$$
\frac{1}{\sqrt{f}}=2 \log (\operatorname{Re} \sqrt{f})-0.8
$$

\section{Darby and Melson (1981) model}

Darby and Melson (1981) modified the BuckinghamReiner equation (3) for Fanning friction factor $\left(C_{f}\right)$ in terms of modified Reynolds number $\left(R e_{m o d}\right)$ as:

$C_{f}=\frac{16}{R e_{\text {mod }}}$ where $R e_{\text {mod }}=\frac{6 R e_{B}^{2}}{6 R e_{B}+H e}$

They also developed an empirical expression for turbulent flow as:

$$
\begin{aligned}
& f_{T}=10^{a} \operatorname{Re}^{-0.193} \\
& a=-1.47\left[1+0.146 e^{-2.9 \times 10^{-5} \mathrm{He}}\right]
\end{aligned}
$$

To get a single explicit friction factor equation valid for all flow regimes, they developed the following relations:

$$
f=\left[f_{L}^{m}+f_{T}^{m}\right]^{\frac{1}{m}}
$$

where $m=1.7+\frac{40000}{\operatorname{Re}}$

\section{Wilson and Thomas (1985)}

They developed a new analytical equation for turbulent flow of non-Newtonian fluids based on velocity profile alteration (drag reduction) associated with thickening of the viscous sublayer and the required flow parameters can be determined directly from a rheogram without employing correlations based on pipe-flow data.

For the Bingham plastic fluids in turbulent flow they developed the following relationships:

$\frac{V}{U_{*}}=2.5 \ln R e_{*}^{\prime}+2.5 \ln \left[(1-\xi)^{2} /(1+\xi)\right]+\xi(14.1+1.25 \xi)$

where $R e_{*}^{\prime}=\rho D U_{*} / \eta_{p} ; \quad \xi=\tau_{y B} / \tau_{w} U_{*}=\sqrt{\tau_{w} / \rho}$

and $\frac{V}{U_{*}}=\sqrt{8 / f}$

$f$ is the Stanton-Moody friction factor.

Corresponding to $\operatorname{Re}_{*}^{\prime}>830$ and $\rho D V / \eta_{t}>1.7 \times 10^{4}$ the following formula would be implemented:

$$
\frac{V}{U_{*}}=2.5 \ln \left(R e_{*}^{\prime}\right)+32
$$

For smaller values of Hedstrom number $(\mathrm{He}<450000)$ the turbulent expression can be based on equation (10) and for laminar regime expression the following is well known:

$\frac{V}{U_{*}}=\frac{\left[3-\xi\left(4-\xi^{3}\right)\right] R e_{*}^{\prime}}{24}$

\section{Slatter (1995) correlation}

He modified the Reynolds number for determining the transition from laminar to turbulent flow for Herschel-Bulkley (and Bingham plastic) slurries as: 


$$
\operatorname{Re}_{\text {mod }}=\frac{8 \rho V_{\text {ann }}{ }^{2}}{\tau_{Y H}+K\left(\frac{8 V_{\text {ann }}}{D_{\text {shear }}}\right)^{n}} \text { and laminar ceases at } R e_{\text {mod }} \leq 2100
$$

where $V_{\text {ann }}=\frac{Q-Q_{\text {plug }}}{\pi\left(R^{2}-R_{\text {plug }}^{2}\right)}$

$D_{\text {shear }}=D-D_{\text {plug }}=2\left(R-R_{\text {plug }}\right)$

$V_{\text {plug }}=\frac{n R}{(n+1)}\left(\frac{\tau_{w}}{K}\right)^{1 / n}(1-\phi)^{(n+1) / n}$

where $\phi=\frac{D_{\text {plug }}}{D}=\frac{\tau_{Y H}}{\tau_{w}}$

$Q=\pi R^{3} n\left(\frac{\tau_{w}}{K}\right)^{1 / n}(1-\phi)^{(n+1)} / n\left\{\frac{(1-\phi)^{2}}{3 n+1}+\frac{2 \phi(1-\phi)}{2 n+1}+\frac{\phi^{2}}{n+1}\right\}$

$Q_{\text {plug }}=\pi D_{\text {plug }}^{2} V_{\text {plug }}$

where $R e_{\text {mod }}=$ Slatter modified Reynolds number, $V_{a n n}=$ velocity in the sheared annulus $(\mathrm{m} / \mathrm{s}), D_{\text {shear }}=$ equivalent diameter of sheared region $(\mathrm{m}), Q=$ transitional volumetric flow rate $\left(\mathrm{m}^{3} / \mathrm{s}\right)$

$R_{H B}=\frac{\rho V^{n-1} D^{n}}{8^{n-1} K}\left(\frac{4 n}{1+3 n}\right)^{n}$ and $f_{f}=\frac{16}{\Psi R_{H B}}$

where $\Psi=(1+3 n)^{n}(1+\phi)^{1+n}\left[\frac{(1-\phi)^{2}}{1+3 n}+\frac{2 \phi(1-\phi)}{1+2 n}+\frac{\phi^{2}}{1+n}\right]$

For Bingham Plastic slurries, set $n=1, \tau_{H B}=\tau_{Y B}$ and $K=\eta_{P}$ This approach was specifically developed to place emphasis on the visco-plastic nature of the material (Slatter, 1995). He also developed a turbulent flow model appropriate for nonNewtonian sludges. A roughness Reynolds number for nonNewtonian sludges was formulated to accommodate the particle roughness effect based on a representative particle size, $d_{85}$, and the Herschel-Bulkley rheological parameters:

$$
\operatorname{Re}_{r}=\frac{8 \rho U_{*}^{2}}{\tau_{Y B}+K\left[\frac{8 U_{*}}{d_{85}}\right]^{n}}
$$

If $R e_{r}<3.32$ then smooth wall turbulent flow exists and the mean velocity is given by:

$\frac{V}{U_{*}}=2.5 \ln \left(\frac{R}{d_{85}}\right)+2.5 \ln \left(R e_{r}\right)+1.75$

If $R e_{r}>3.32$ then fully developed rough wall turbulent flow exists and the mean velocity is given by:

$\frac{V}{U_{*}}=2.5 \ln \left(\frac{R}{d_{85}}\right)+4.75$ where $R$ is the inside radius of the pipe.

\section{Danish-Kumar solution}

Danish et al. (2011) have provided an explicit procedure to calculate the friction factor by using the Adomian decomposition method. The friction factor containing two terms through this method for laminar flow is given as:

$$
f_{L}=\frac{K_{1}+\frac{4 K_{2}}{\left(K_{1}+\frac{K_{1} K_{2}}{K_{1}^{4}+3 K_{2}}\right)^{3}}}{1+\frac{3 K_{2}}{\left(K_{1}+\frac{K_{1} K_{2}}{K_{1}^{4}+3 K_{2}}\right)^{4}}}
$$

where $K_{1}=\frac{16}{R e}+\frac{16 H e}{6 R e^{2}}$ and $K_{2}=-\frac{16 H e^{4}}{3 R e^{8}}$

and for turbulent flow:

$$
\begin{aligned}
& \frac{1}{2 \sqrt{f}}=C_{\mathrm{o}}-\frac{1.73718 C_{\mathrm{o}}\left(\ln C_{\mathrm{o}}\right)}{1.73718+C_{\mathrm{o}}}+\frac{2.62122 C_{\mathrm{o}}\left(\ln C_{\mathrm{o}}\right)^{2}}{\left(1.73718+C_{\mathrm{o}}\right)^{3}}+ \\
& +\frac{3.03568 C_{\mathrm{o}}\left(\ln C_{\mathrm{o}}\right)^{3}}{\left(1.73718+C_{\mathrm{o}}\right)^{4}}
\end{aligned}
$$

where $C_{\mathrm{o}}=4 \log _{10} R e-0.4$

For the flow of Bingham fluids to be in the laminar regime, the Reynolds number for a given Hedstrom number should be less than the corresponding critical Reynolds number.

\section{Swamee-Aggarwal equation (2011)}

This equation is used to solve directly for the DarcyWeisbach friction factor $f_{L}$ for laminar flow of Bingham plastic fluids. It is an approximation of the implicit Buckingham Reiner equation, but the discrepancy from experimental data is well within the accuracy of the data. It is given by:

$$
f_{L}=\frac{64}{R e}+\frac{10.67+0.1414\left(\frac{H e}{R e}\right)^{1.143}}{\left[1+0.0149\left(\frac{H e}{R e}\right)^{1.16}\right] \operatorname{Re}}\left(\frac{H e}{R e}\right)
$$

\section{Morrison correlation (2013)}

It is occasionally desirable to have a data correlation that spans the entire range of Reynolds number, from laminar flow, through transitional flow, and reaching the highest values of Reynolds number. For this Morrison (2013) developed a new data correlation for smooth pipes which is more explicit and relatively simple in form.

$C_{f}=\left[\frac{0.0076\left(\frac{3170}{R e}\right)^{0.165}}{1+\left(\frac{3170}{R e}\right)^{7.0}}\right]+\frac{16}{R e}$ 
At lower Reynolds number this equation become (16/Re) and at high Reynolds numbers $\left(4000 \leq R e \leq 10^{6}\right)$ this equation follows the Prandtl correlation, the smooth-pipe equivalent and original source of the Colebrook equation.

\section{Transitional flow}

The value of the Darcy friction factor may be subject to large uncertainties in this flow regime. For uniformity the range of Reynolds number for laminar-turbulent flow proposed by Hanks and Pratt (1967) were remained in between 2100 to 4000, valid for all correlations in this review except for some equations which do have their own critical Reynolds number formula or values.

\section{STATISTICAL ANALYSIS AND MODELS COMPUTATIONS}

In order to compare predicted friction factor $\left(f_{\mathrm{M}, \text { pred }}\right)$ with experimental data $\left(f_{\mathrm{M}, \mathrm{exp}}\right)$, eight commonly used statistical parameters were implemented based on the literature recommendations (García et al., 2003, 2005, 2007; Genić et al., 2011; Gregory and Fogarasi, 1985; Ouyang, 1998; Xiao et al., 1990). The parameters involved in the models comparison with their details interpretations are listed in Table S2 in Supplementary material.

From research works of Sunil et al. (2009, 2010), the experimental data for pressure drops for the flow of fly ash having specific gravity of 1.992 through a smooth pipe of 40 $\mathrm{mm}$ diameter in the range of velocity from 1 to $3 \mathrm{~m} / \mathrm{s}$ and concentration by weight from 60 to $70 \%$ were reproduced by plot digitizer 2.6.6 and used to get the experimental friction factors. The friction factor is computed as:

$$
f=\left(\frac{\Delta P}{L}\right)\left(\frac{2 D}{\rho U^{2}}\right)
$$

Details of the experimental data for rheological properties are reported in Table S1 of the Appendix. The friction factors of observed data were computed by equation (21) and the comparison between these values and friction factors estimated by the correlation models (Table S3 in Supplementary material) are shown in Figure 1. In this Figure $R e$ is the Reynolds number.

\section{EVALUATION OF THE SELECTED FRICTION FACTOR CORRELATIONS}

Based on the statistical parameters analysis, the majority of the model predictions have RMSE and S values less than $20 \%$ (Table 1). Equation (20) showed best results according to all the listed criteria in laminar flow. It is interesting that equations (7), (17), and (19) for laminar flow have the same values in all statistical parameters. But equation (19) should be given the advantage because of its simplicity in calculation. The analysis for laminar flow showed that both equations (1) and (12) have the same values in terms of relative errors and degree of correlation with the experimental data but equation (1) showed less data variability with in the estimated values. Even though equations (10) and (20) have the same minimum error and better regression estimations in all flow regimes, equation (20) is superior in terms of less number of input parameters and ease

Table 1. Calculated values of statistical parameters for the selected models.

\begin{tabular}{|c|c|c|c|c|c|c|c|c|c|}
\hline Flow & Eqn $^{*}$ & MARE & $\mathrm{MRE}^{+}$ & $\mathrm{MRE}^{-}$ & RMSE & $S$ & $\theta$ & AIC & $\mathrm{MSC}$ \\
\hline \multirow{7}{*}{$\begin{array}{l}\text { 节 } \\
\text { 奇 }\end{array}$} & 1 & 10.63 & 2.93 & -27.5 & 12.4 & 6.897 & 0.954 & -95.25 & -35.75 \\
\hline & 4 & 7.68 & 9.37 & -23.3 & 9.09 & 6.91 & 0.969 & -109.94 & -35.27 \\
\hline & 5 & 6.72 & 15.18 & -24.87 & 8.3 & 11.06 & 0.971 & -111.66 & -34.54 \\
\hline & 6 & 10.43 & 7.01 & -31.44 & 13.57 & 10.24 & 0.95 & -92.51 & -35.63 \\
\hline & 7 & 7.68 & 9.37 & -24.8 & 9.09 & 6.91 & 0.969 & -109.94 & -35.27 \\
\hline & 8 & 7.68 & 9.37 & -24.8 & 9.09 & 6.91 & 0.969 & -109.94 & -35.27 \\
\hline & 9 & 2.994 & 5.18 & -12.2 & 4.14 & 4.11 & 0.994 & -169.56 & -33.27 \\
\hline \multirow{7}{*}{$\begin{array}{l}\stackrel{\overrightarrow{0}}{\Xi} \\
\stackrel{\Xi}{\Xi}\end{array}$} & 2 & 17.75 & 25.91 & -27.5 & 20.07 & 20.02 & 0.662 & -113.41 & -36.3 \\
\hline & 3 & 16.25 & 24.97 & -28.8 & 18.48 & 18.23 & 0.702 & -116.76 & -42.09 \\
\hline & 4 & 16.42 & 4.23 & -23.3 & 18.41 & 18.52 & $* *$ & -90.12 & -38.10 \\
\hline & 5 & 10.12 & 28.52 & -30.88 & 12.83 & 14.62 & 0.732 & -119.74 & -35.68 \\
\hline & 6 & 47.39 & 68.9 & -56.12 & 50.15 & 41.9 & $* *$ & -91.68 & -37.98 \\
\hline & 8 & 16.24 & 23.51 & -24.8 & 18.53 & 18.51 & 0.691 & -115.79 & -42.21 \\
\hline & 9 & 14.07 & 13.75 & -13.2 & 12.62 & 12.64 & 0.923 & -130.55 & -32.42 \\
\hline \multirow{7}{*}{ 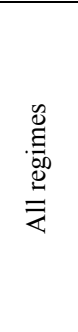 } & $1 \& 3$ & 13.28 & 24.97 & -27.5 & 15.45 & 15.45 & 0.963 & -155.68 & -34.32 \\
\hline & $7 \& 2$ & 12.43 & 25.91 & -28.8 & 15.16 & 15.17 & 0.971 & -171.92 & -33.73 \\
\hline & 4 & 16.38 & 9.37 & -23.3 & 21.73 & 21.78 & 0.959 & -148.51 & -34.88 \\
\hline & 5 & 8.32 & 28.52 & -30.88 & 11.86 & 11.86 & 0.973 & -178.94 & -33.50 \\
\hline & 6 & 28.14 & 68.9 & -56.15 & 35.87 & 35.91 & 0.945 & -133.73 & -32.28 \\
\hline & 8 & 11.71 & 23.51 & -24.8 & 14.23 & 14.23 & 0.971 & -173.84 & -33.76 \\
\hline & 9 & 6.57 & 13.75 & -13.2 & 12.36 & 12.34 & 0.984 & -214.45 & -32.03 \\
\hline
\end{tabular}

\footnotetext{
${ }^{*}$ The models corresponding to the equations number are listed in Table S2 in Supplementary material.
}

** The correlation ratio is undefined. 


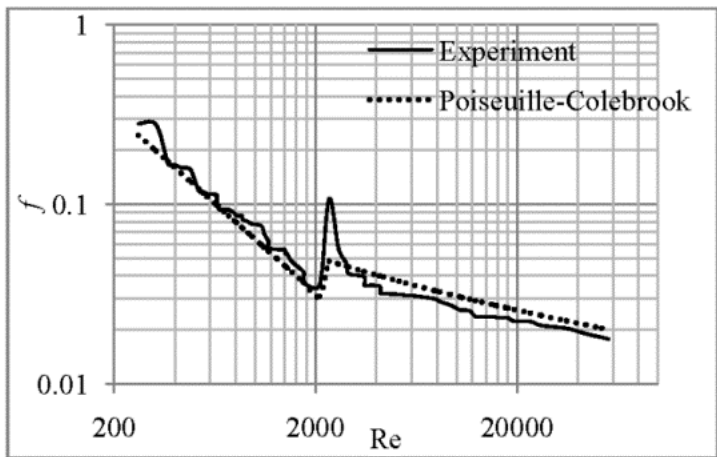

(a)

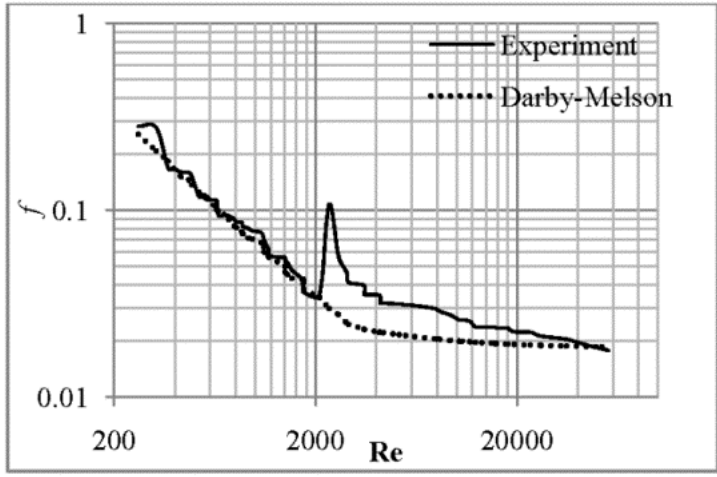

(c)

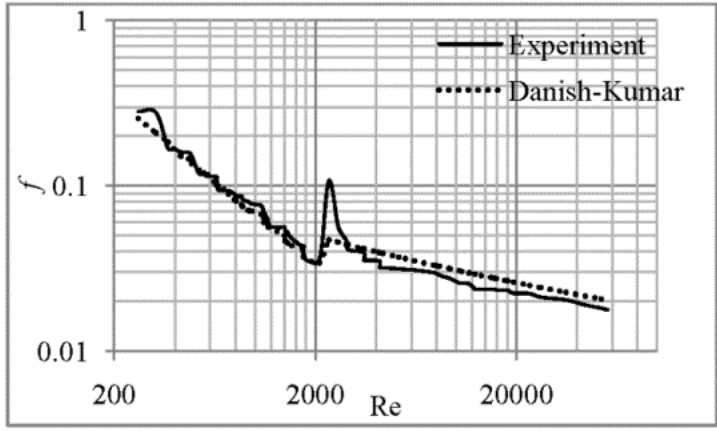

(e)

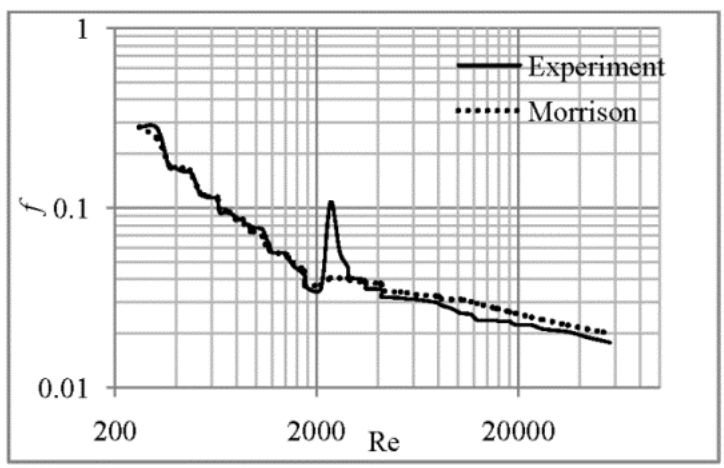

(g)

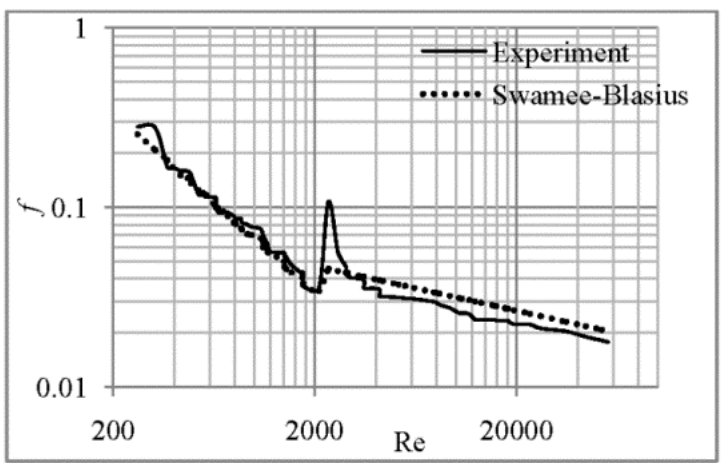

(b)

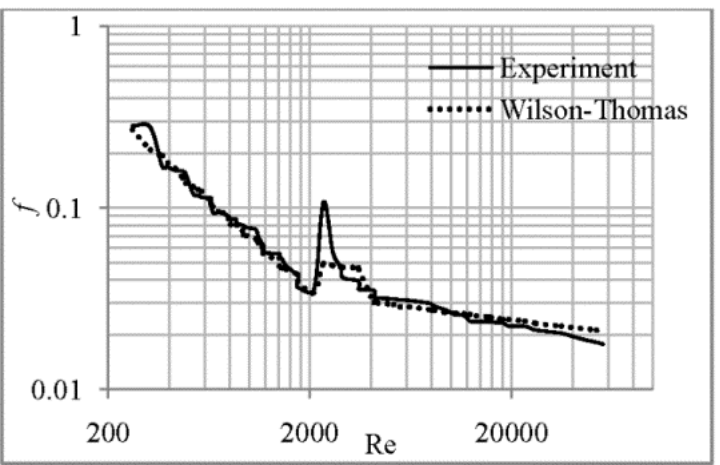

(d)

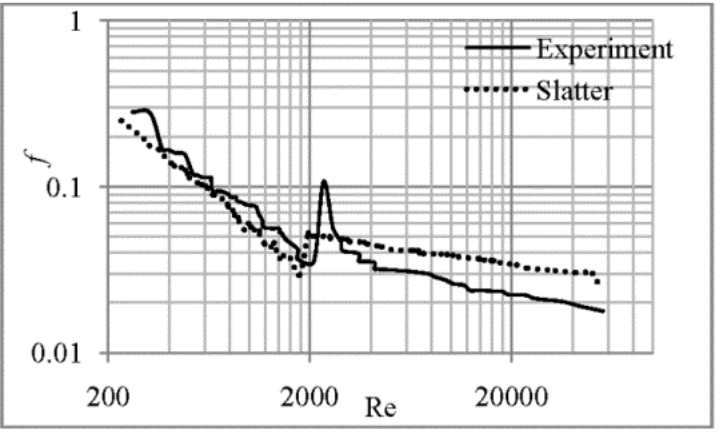

(f)

Fig. 1. Comparison of experimental data with predicted friction factors in smooth pipe.

of calculation requirements. Another important feature observed is that for a transitional and turbulent regime $(R e \cong 3000$ 400000), equation (10) has minimum error followed by equation (20) but showed high variability in terms of data representation (Fig. 2e and Table 1) and show high rate of increment of relative error beyond $40000 \mathrm{Re}$ which likewise is also explained by Wilson and Thomas (1985). Equation (15) failed to predict and shows highest variability and greatest deviation from the experimental data. Similar observations were made by El-Nahhas and Mostafa (2006).

Estimations have also been done by combining different correlations for laminar and turbulent flow developed separately by various researchers, for instance combining equation (1) with (5), and equation (19) with (2). In this aspect, results obtained by combining equation (19) with (2) showed better results in terms of mean absolute relative $\%$ error (MARE), root mean square 


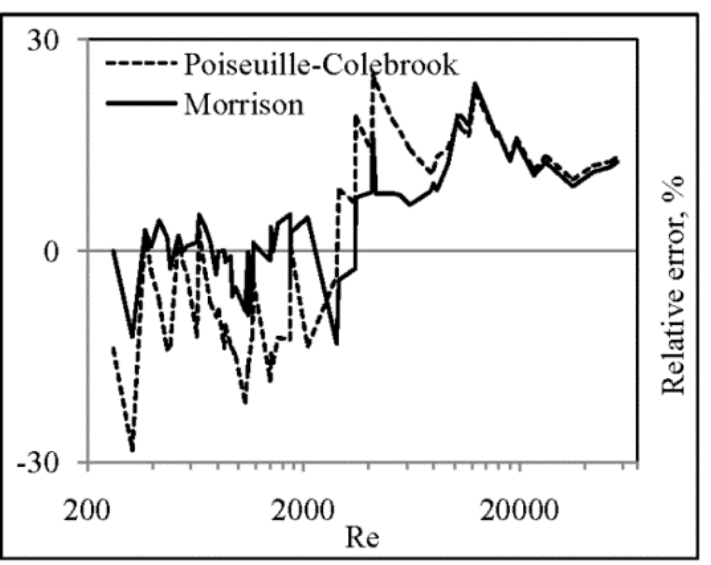

(a)

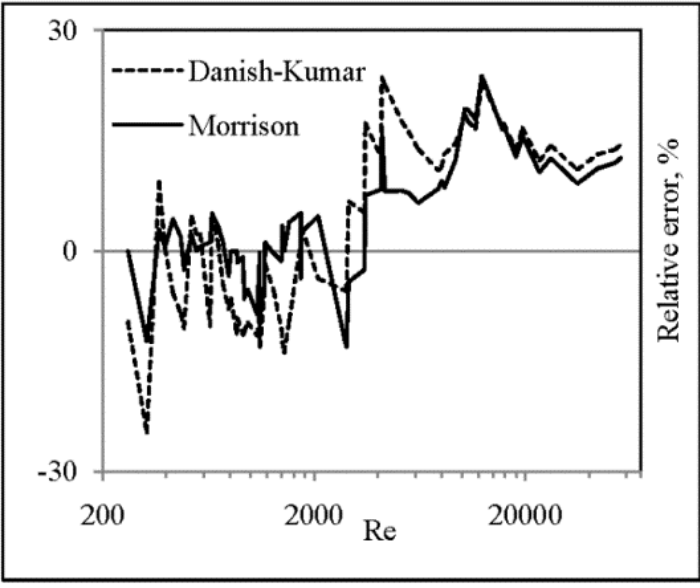

(c)

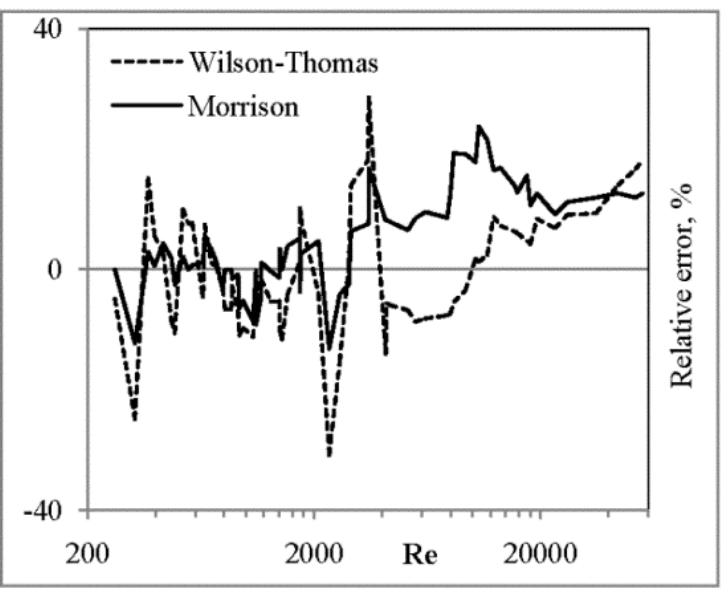

(e)

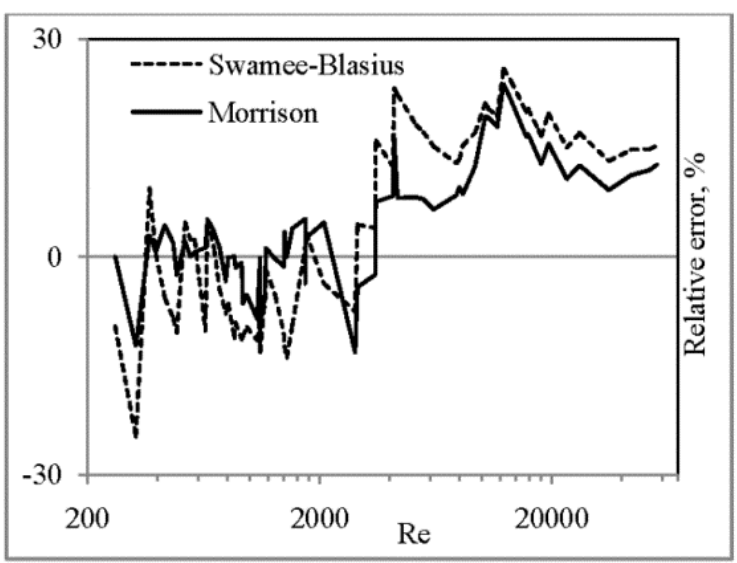

(b)

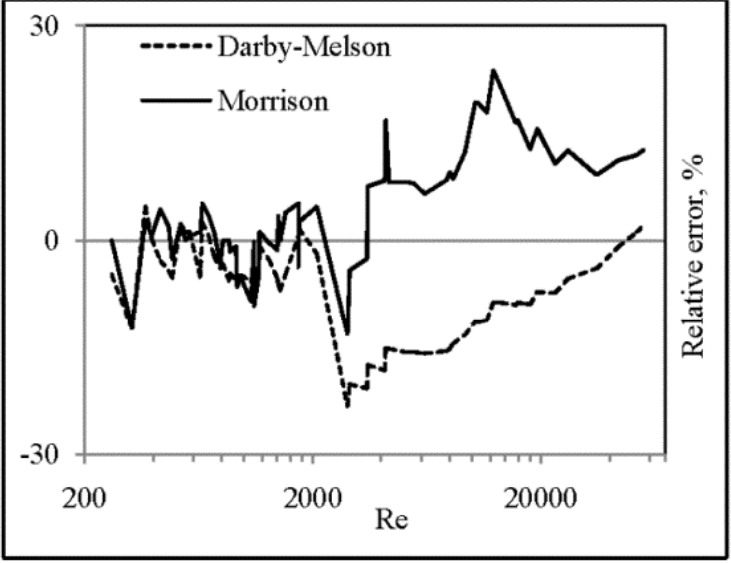

(d)

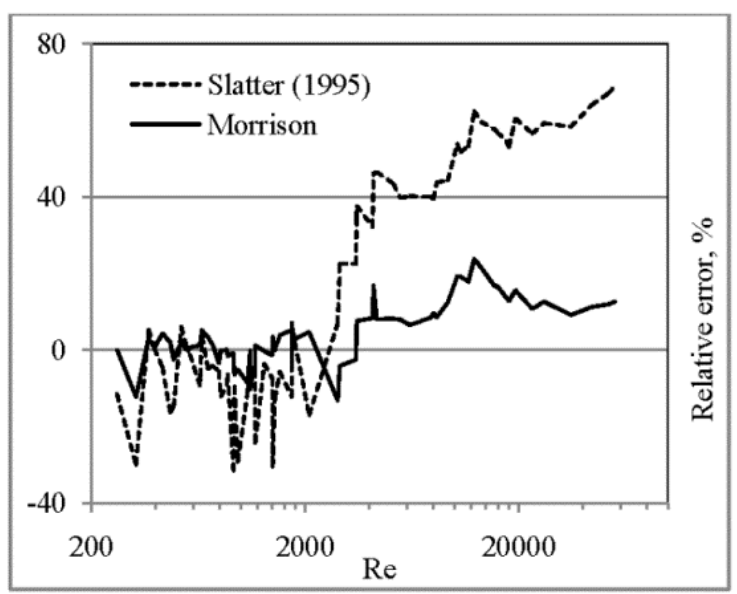

(f)

Fig. 2. Comparison of the relative error of Morrison equation (20) with the remaining models as a function of the Reynolds number $R e$.

error (RMSE), standard deviation of MARE (S), and correlation ratio $(\Theta)$ than equation $(9)$ in overall estimation. This notion will motivate for further investigations and improving the accuracy of the data. In general the performance of equation (20) for the estimation of friction factors in smooth pipes is excellent with relative deviation of $\pm 15 \%$ followed by equation $(10-11)$. The relative errors of the other models were compared with equation (20) as displayed in Fig. 2.

As shown in Fig. 1, Darby-Melson (1981) model underpredicts the friction factors for all flow regimes. But the other models under-predict the friction factors in laminar flow and over predict for turbulent flows for the given maximum ranges of Reynolds number. The extent of under-prediction by the Darby- Melson model for turbulent flow is much higher than the over-prediction by the other models except Blasius (1939) and Slatter (1995) model. For turbulent flow in smooth pipes, the Slatter (1995) equation is the least accurate, whereas the Wilson-Thomas (1985) model has the highest accuracy followed by Morrison (2013) and Danish-Kumar (2011) equation. 


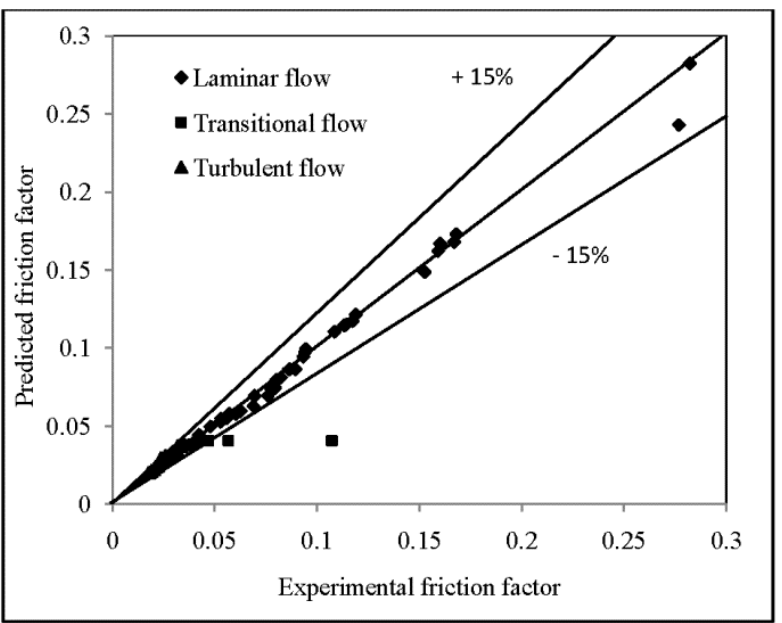

Fig. 3. Comparison of the Morrison's model data with the experimental data for $\pm 15 \%$ deviation.

\section{CONCLUSIONS AND RECOMMENDATION}

- Experimental data of rheology and pressure drops were collected from literature for flow of Bingham-plastic fluids through smooth pipes at different solid concentrations and flow velocities.

- Nine explicit equations have been chosen to estimate the friction factor in laminar, and/or turbulent flows in smooth pipes. All the equations were compared with experimental data statistically.

- The Morrison (2013) is the only equation representing a friction factor for all flow regimes with single equation (Fig. 3). The Darby-Melson (1981), Wilson-Thomas (1985), Slatter (1995) and Danish-Kumar (2011) developed separate equations for each flow regimes. By combining different formulas (such as Hagen-Poiseuille (1840) with Colebrook equation, and Swamee-Aggarwal (2011) with Blasius (1913)), the statistical analysis and comparisons with experimental data were made for all flow regimes.

- The Wilson-Thomas (1985) and Morrison (2013) models are found to be the best fit models to the experimental data in the range up to $40000 \mathrm{Re}$. Within this range both the models can be used alternately. But beyond this Re, the discrepancy of WilsonThomas model is higher than the Morrison model.

- In view of the fact that the Morrison model requires fewer calculations and parameters as well as all flow regimes being computed by a single equation, it is the authors' advice to use this model for friction factor estimation of Bingham fluids in smooth pipes as an alternative to the Moody chart and to other implicit formulas.

- The results obtained by Morrison (2013) correlation can be used as an initial guess for Adomian Decomposition Method (ADM) and Restarted Adomian Decomposition Method (RADM) used in Danish et al. (2011) correlation equation to get better results.

\section{REFERENCES}

Bingham Plastic. Wikipedia: the free encyclopaedia. Retrieved on May10, 2014 from http://en.wikipedia.org/wiki/Bingham_plastic

Blasius, H., 1913. Das Aehnlichkeitsgesetz bei Reibungsvorgangen in Flussigkeiten. [The Law of Similarity in Friction
Processes in Liquids]. VDI Mitt. Forschungsarb., 131, 1-39. (In German.)

Buckingham, E., 1921. On plastic flow through capillary tubes. ASTM Proceeding, 21, 1154-1161.

Colebrook, C.F., 1938-1939. Turbulent flow in pipes with particular reference to the transition region between the smooth and rough pipe laws. Journal of the Institution of Civil Engineering, 11, 133-156.

Danish, M., Kumar, S., Kumar, S., 2011. Approximate explicit analytical expressions of friction factor for flow of Bingham fluids in smooth pipes using Adomian Decomposition Method. Commun. Nonlinear Sci. Numer. Simulat., 16, 1, 239-251.

Darby, R., Melson, J., 1981. How to predict the friction factor for flow of Bingham Plastics. Chemical Engineering, 28, 59-61.

Darcy friction factor formulae. Wikipedia: The free encyclopaedia. Retrieved on September 21, 2014 from http://en.wikipedia.org/wiki/Darcy_friction_factor_formulae

El-Nahhas, K., Mostafa, N.H., 2006. Prediction of nonNewtonian turbulent flow behavior by a Newtonian approach. In: Proc. $10^{\text {th }}$ International Water Technology Conference, IWTC10, Alexandria, Egypt, pp. 479-490.

Fang, X.D., Xu, Y., Zhou, Z.R., 2011. New correlations of single-phase friction factor for turbulent pipe flow and evaluation of existing single-phase friction factor correlations. Nuclear Engineering and Design, 241, 897-902.

García, F., García, R., Padrino, J.C., Mata, C., Trallero, J., Joseph, D., 2003. Power law and composite power law friction factor correlations for laminar and turbulent gasliquid flow in horizontal pipelines. Int. J. Multiphase Flow, $29,10,1605-1624$.

García, F., García, R., Joseph, D., 2005. Composite power law hold up correlations in horizontal pipes. Int. J. Multiphase Flow, 31, 12, 1276-1303.

García, F., García, J.M., García, R., Joseph, D., 2007. Friction factor improved correlations for laminar and turbulent gasliquid flow in horizontal pipelines. Int. J. Multiphase Flow, $33,1320-1336$.

Genić, S., Arandjelović, I., Kolendić, P., Jarić, M., Budimir, N., Genić, V., 2011. A review of explicit approximations of Colebrook's equation. FME Transactions, 39, 67-71.

Gregory G. A., Fogarasi, M., 1985. Alternate to standard friction factor equation. Oil Gas Journal, 83, 13, 120-127.

Hanks, R.W., Pratt, D.R., 1967. On the flow of Bingham Plastic slurries in pipes and between parallel plates. Journal of Society of Petroleum Engineers, 1682, 342-346.

Moody, L., 1944. Friction factors for pipe flow. Trans. ASME, $66,8,671-684$.

Morrison, F.A., 2013. Data correlation for friction factor in smooth pipes. Department of Chemical Engineering, Michigan Technological University, Houghton, MI.

Ouyang, L., 1998. Single phase and multiphase fluid flow in horizontal wells. Ph.D. Dissertation Thesis. Dept. of Petro. Eng., School of Earth Sciences. Stanford Univ., 248 p.

Prandtl, L., 1935. The mechanics of viscous fluids. In: Durand, W.F. (Ed.): Aerodynamic Theory, 3, 34-208.

Slatter, P.T., 1995. The turbulent flow of non-Newtonian slurries in pipe. In: Proc. $8^{\text {th }}$ Conference on Transport and sedimentation of solid particles. Prague, A3.

Sunil, C., Seshadri, V., Singh, S.N., 2009. Effect of additive on pressure drop and rheological characteristics of fly ash slurry at high concentration. Particulate Science and Technology, $27,3,271-284$. 
Sunil, C., Seshadri, V., Singh, S.N., 2010. Transportation of high concentration coal ash slurries through pipelines. International Archive of Applied Science and Technology, 1, 1.

Swamee, P.K., Aggarwal, N., 2011. Explicit equations for laminar flow of Bingham Plastic fluids. Journal of Petroleum Science and Engineering, 76, 178-184.

Swamee, P., Jain, A., 1976. Explicit equations for pipe flow problems. Journal of the Hydraulics Division (ASCE), 102, $5,657-664$.

Xiao, J.J., Shonham, O., Brill, J.P., 1990. A comprehensive mechanistic model for two-phase flow in pipelines. In: Proc. $65^{\text {th }}$ SPE Annual Technical Conference and Exhibition, New Orleans, LA, Paper SPE 20631, pp. 167-180.

Wilson K.C., Thomas, A.D., 1985. New analysis of the turbulent flow of non-Newtonian fluids. Canadian Journal of Chemical Engineering, 63, 539-546.

\begin{tabular}{|c|c|c|c|}
\hline \multicolumn{4}{|c|}{ Notation } \\
\hline$C_{f}$ & $\begin{array}{l}\text { Fanning friction } \\
\text { factor }\end{array}$ & $f_{a v, \exp }$ & $\begin{array}{l}\text { Average friction factor of } \\
\text { the experimental data }\end{array}$ \\
\hline$f$ & $\begin{array}{l}\text { Darcy-Weisbach } \\
\text { friction factor }\end{array}$ & $f_{\text {exp }}$ & $\begin{array}{l}\text { Experiment friction } \\
\text { factor }\end{array}$ \\
\hline $\operatorname{Re}$ & Reynolds number & $f_{\text {pred }}$ & Predicted friction factor \\
\hline$U$ & $\begin{array}{l}\text { Mean velocity of } \\
\text { the mixture }(\mathrm{m} / \mathrm{s})\end{array}$ & $n$ & $\begin{array}{l}\text { Number of experimental } \\
\text { data }\end{array}$ \\
\hline$\rho_{m}$ & $\begin{array}{l}\text { Density of mixture } \\
\left(\mathrm{kg} / \mathrm{m}^{3}\right)\end{array}$ & $R e_{\text {mod }}$ & $\begin{array}{l}\text { Modified Reynolds } \\
\text { number }\end{array}$ \\
\hline$\eta_{p}$ & $\begin{array}{l}\text { Dynamic viscosity } \\
\text { (Pa.S) }\end{array}$ & $\mathrm{He}$ & Hedstrom number \\
\hline$\tau_{y}$ & $\begin{array}{l}\text { Yield shear stress } \\
(\mathrm{Pa})\end{array}$ & $\overline{f_{L}}$ & $\begin{array}{l}\text { Friction factor for lami- } \\
\text { nar flow }\end{array}$ \\
\hline$D$ & Pipe diameter $(\mathrm{m})$ & $\overline{f_{T}}$ & $\begin{array}{l}\text { Friction factor for turbu- } \\
\text { lent flow }\end{array}$ \\
\hline$N P$ & $\begin{array}{l}\text { Number of parame- } \\
\text { ters in the equation }\end{array}$ & & \\
\hline
\end{tabular}

Received 17 July 2014 Accepted 3 November 2014

Note: Supplementary Tables (S1-S3) can be found in the web version of this article. 


\section{SUPPLEMENTARY MATERIAL}

Table S1. Details of rheological data considered in the present study (Sunil et al., 2009 and 2010).

\begin{tabular}{lcc}
\hline Weight conc $(\%)$ & Yield stress & Slurry viscosity \\
& $\left(\tau_{v}\right)[\mathrm{Pa}]$ & $\left(\eta_{p}\right)\left(* 10^{-3}\right)[\mathrm{Pa} \mathrm{s}]$ \\
\hline 60 & 0.36 & 14.5 \\
65 & 1.36 & 53.4 \\
68 & 1.712 & 172.1 \\
70 & 1.945 & 245.3 \\
\hline
\end{tabular}

Table S2. Governing equation of the statistical parameters and their interpretations.

\begin{tabular}{|c|c|c|c|}
\hline No. & Statistical parameter & Governing equations & Interpretation \\
\hline 1 & $\begin{array}{l}\text { Mean Absolute Relative } \\
\text { Error }[\%]\end{array}$ & $\begin{array}{c}\text { MARE, } \%=\frac{1}{n} \sum_{i=1}^{n}\left|r_{i}\right| \\
\text { where } r_{i}=\left(\frac{e_{i}}{f_{M, \exp }}\right) \times 100 \text { and } \\
e_{i}=f_{M, \text { pred }}-f_{M, \exp }\end{array}$ & $\begin{array}{l}\text { The smaller the value the better the } \\
\text { model }\end{array}$ \\
\hline 2 & $\begin{array}{l}\text { Root Mean Square Error } \\
{[\%]}\end{array}$ & $R M S E, \%=\sqrt{\frac{1}{n} \sum_{i=1}^{n}\left(r_{i}\right)^{2}}$ & $\begin{array}{l}\text { The better the regression estimate, the } \\
\text { smaller the size of the errors }\end{array}$ \\
\hline 3 & $\begin{array}{l}\text { Standard deviation of } \\
\text { MARE }\end{array}$ & $\begin{array}{c}S=\sqrt{\frac{1}{n} \sum_{i=1}^{n}\left(r_{i}-E_{1}\right)^{2}} \\
\text { where } E_{1}=\frac{1}{n} \sum_{i=1}^{n} r_{i}\end{array}$ & $\begin{array}{l}\text { Lower percentage indicates a lower } \\
\text { variability in the data }\end{array}$ \\
\hline 4 & Correlation ratio & $\begin{array}{c}\theta=\sqrt{1-\frac{\sum_{i=1}^{n}\left(f_{M, \exp }-f_{M, \text { pred }}\right)^{2}}{\sum_{i=1}^{n}\left(f_{M, \exp }-f_{a v, \exp }\right)^{2}}} \\
\text { where } f_{a v, \exp }=\frac{\sum_{i=1}^{n} f_{M, \exp }}{n}\end{array}$ & $\begin{array}{l}\text { Higher value indicate close correlations } \\
\text { between samples }\end{array}$ \\
\hline 5 & $\begin{array}{l}\text { Akaike Information } \\
\text { Criterion }\end{array}$ & $A I C=n \ln \left[\sum_{i=1}^{n}\left(e_{i}\right)^{2}\right]+2 N P$ & $\begin{array}{l}\text { The most appropriate model is the one } \\
\text { with the smallest values }\end{array}$ \\
\hline 6 & Model selection criterion & $M S C=\ln \left|\frac{\sum_{i=1}^{n}\left(f_{M, \exp }-f_{a v, \exp }\right)}{\sum_{i=1}^{n}\left(f_{M, \text { pred }}-f_{M, \exp }\right)}\right|-\frac{2 N P}{n}$ & $\begin{array}{l}\text { The most appropriate model is the one } \\
\text { with the largest MSC }\end{array}$ \\
\hline
\end{tabular}

$N P=$ the number of parameters in the model or equivalently the number of degrees of freedom and $n=$ the number of sample data size 
Table S3. Selected explicit equations for the calculation of the friction factor of Bingham plastic fluids in smooth pipes.

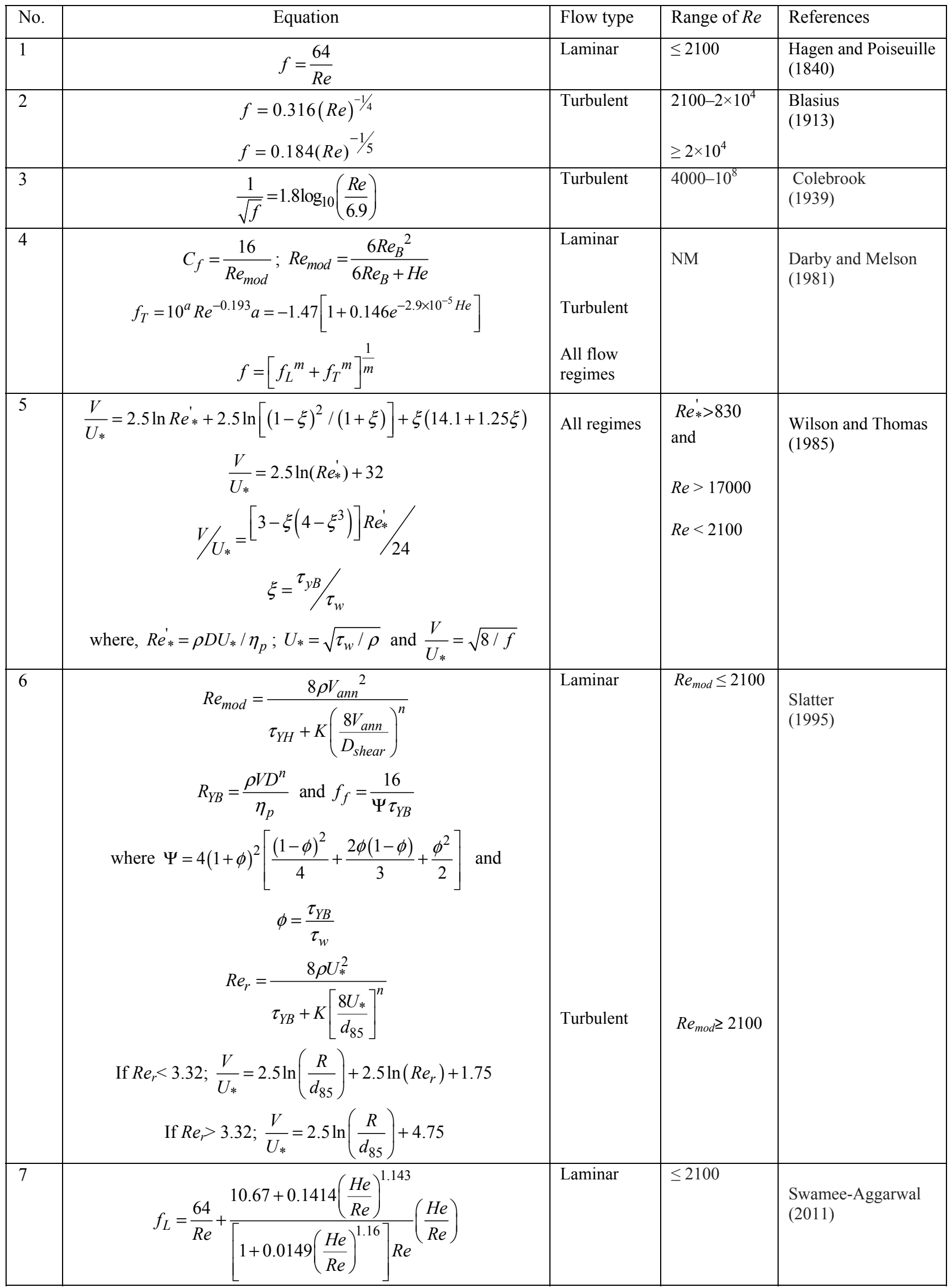




\begin{tabular}{|c|c|c|c|c|}
\hline 8 & $\begin{array}{c}f_{L}=\frac{K_{1}+\frac{4 K_{2}}{\left(K_{1}+\frac{K_{1} K_{2}}{K_{1}^{4}+3 K_{2}}\right)^{3}}}{1+\frac{3 K_{2}}{\left(K_{1}+\frac{K_{1} K_{2}}{K_{1}^{4}+3 K_{2}}\right)^{4}}} \\
K_{1}=\frac{16}{R e}+\frac{16 H e}{6 R e^{2}} ; K_{2}=-\frac{16 H e^{4}}{3 R e^{8}} \\
\frac{1}{2 \sqrt{f}}=C_{\mathrm{o}}-\frac{1.73718 C_{\mathrm{o}}\left(\ln C_{\mathrm{o}}\right)}{1.73718+C_{\mathrm{o}}}+ \\
+\frac{2.62122 C_{\mathrm{o}}\left(\ln _{\mathrm{o}}\right)^{2}}{\left(1.73718+C_{\mathrm{o}}\right)^{3}}+\frac{3.03568 C_{\mathrm{o}}\left(\ln C_{\mathrm{o}}\right)^{3}}{\left(1.73718+C_{\mathrm{o}}\right)^{4}} \\
\text { where } C_{\mathrm{o}}=4 \log _{10} \operatorname{Re}-0.4\end{array}$ & Laminar & NM & $\begin{array}{l}\text { Danish-Kumar } \\
\text { (2011) }\end{array}$ \\
\hline 9 & $C_{f}=\left[\frac{0.0076\left(\frac{3170}{R e}\right)^{0.165}}{1+\left(\frac{3170}{R e}\right)^{7.0}}\right]+\frac{16}{R e}$ & $\begin{array}{l}\text { All flow } \\
\text { regimes }\end{array}$ & $\begin{array}{l}\leq 2100 \\
4000-10^{8}\end{array}$ & $\begin{array}{l}\text { Morrison } \\
\text { (2013) }\end{array}$ \\
\hline
\end{tabular}

NM: Not mentioned 